\title{
Linfangite simples em muar: relato de caso
}

lara Nóbrega Macedo, Sara Vilar Dantas Simões, Karla Campos Malta, Ruy Brayner de Oliveira Filho, Francisca Mônica Couras

Dias, Isabella de Oliveira Barros, Igor Mariz Dantas

Universidade Federal da Paraíba (UFPB), Areia, PB, Brasil

*Autor correspondente

e-mail: doutorabella@hotmail.com

\section{Resumo}

A linfangite é uma inflamação progressiva dos vasos linfáticos periféricos, geralmente decorrente da ação de microorganismos como bactérias e fungos. Existe a linfangite ulcerativa e a linfangite epizoótica, que podem ser de etiopatogenia primária, porém a ocorrência mais comum é a de etiopatogenia secundária à contaminação de lesões cutâneas por bactérias e fungos, ou seja, a linfangite aguda ou simples. 0 presente trabalho tem por objetivo relatar um caso de linfangite simples no membro posterior direito de um muar, SRD, fêmea, de idade desconhecida. 0 animal foi encaminhado ao Hospital Veterinário da Universidade Federal da Paraíba (UFPB) apresentando membro posterior direito edemaciado. Como era um animal errante, não foi detalhado na anamnese se ele havia tido uma lesão cutânea antes do aparecimento dos sinais clínicos, podendo esta ter sido a porta de entrada de microrganismos. 0 paciente apresentava parâmetros vitais dentro da normalidade. Devido à escassez de trabalhos que relatem casos semelhantes, o tratamento adotado para este caso clínico foi baseado no da linfangite ulcerativa. 0 protocolo foi instituído inicialmente à base de penicilina ( $40.000 \mathrm{UI} / \mathrm{kg}$, a cada 48 horas, intramuscular, durante cinco dias) e cetoprofeno (2,2 mg/ $\mathrm{kg}$, intravenoso, a cada 24 horas, cinco dias). Posteriormente, foi introduzido ao tratamento sulfametoxazol e trimetoprima $25 \mathrm{mg} / \mathrm{kg}$, intramuscular, a cada 24 horas, durante cinco dias. Como não foi observada melhora no quadro clínico do paciente com o uso de sulfametoxazol, o animal novamente voltou ao protocolo inicial de antibióticos, com uso de penicilina. Para tentar a redução do edema, utilizou-se dexametazona 0,2 mg/ $\mathrm{kg}$, a cada 24 horas, durante 21 dias, sendo posteriormente feito o desmame. Como complementação do tratamento, realizou-se ducha diária durante 15 minutos, duas vezes ao dia, sendo realizada em todo período de internamento do paciente, assim como massagem com dimetilsulfóxido. Após 57 dias de tratamento, o muar recebeu alta apresentando redução do edema bastante significativa. Desta maneira, é notório que casos de linfangites são poucos descritos na literatura, principalmente casos que apresentem diagnóstico 
real da causa ou ausência de lesões cutâneas, como no relato acima, sendo a patogênese pouco entendida. Apesar disso, é possível observar que se trata de um caso de linfangite aguda ou simples, em que o edema se manifesta principalmente de maneira unilateral no membro afetado. 0 tratamento precoce é fundamental para sua eficácia e recuperação do animal, impedindo desta forma a progressão do edema.

Palavras-chave: Edema. Pele. Sistema linfático. 